\title{
JAS
}

Journal of Analytical Atomic Spectrometry www.rsc.org/jaas

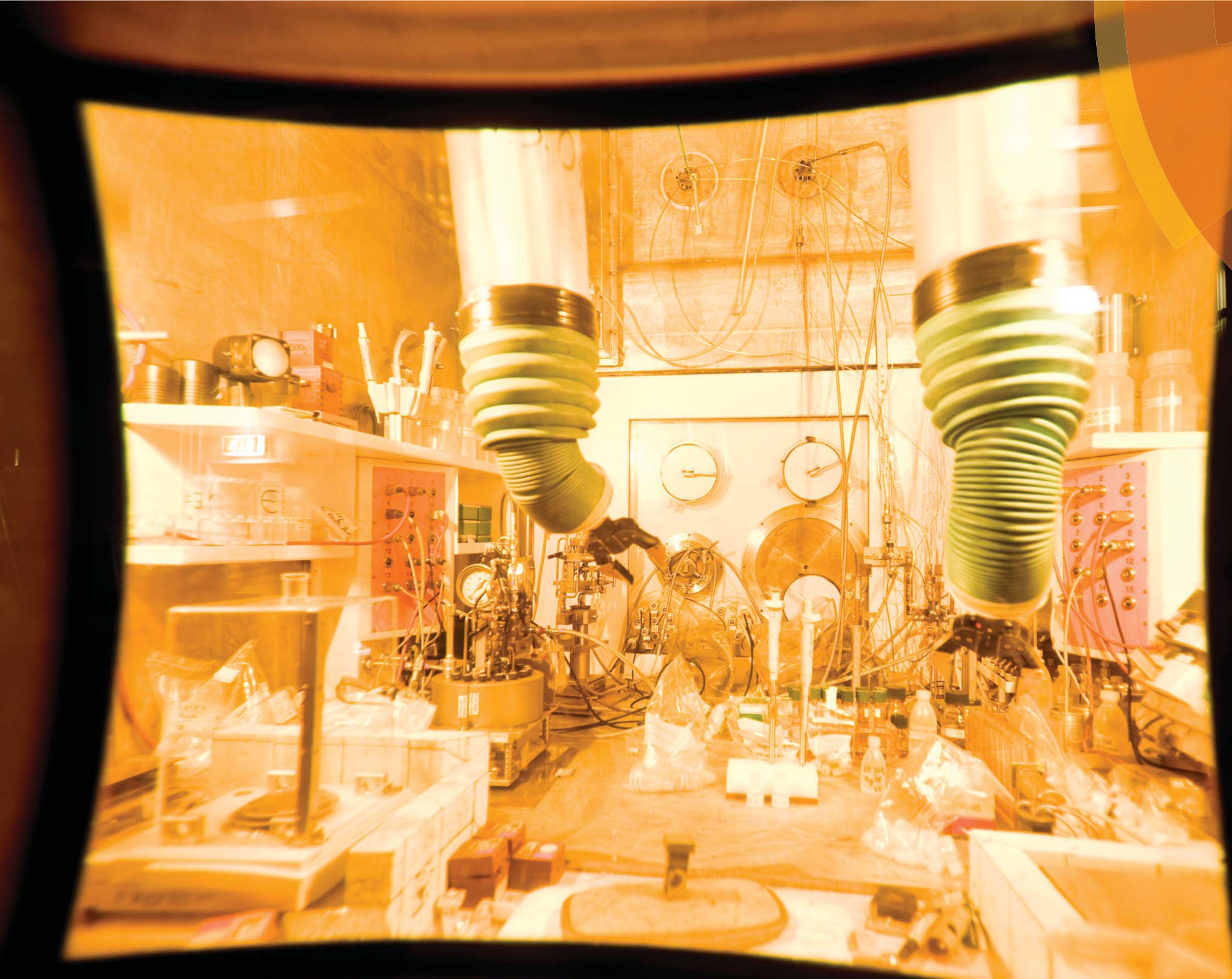

ISSN 0267-9477

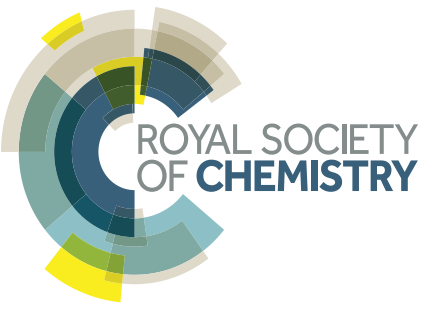

\section{HOT PAPER}

Michael Krachler et al.

Elemental and isotopic analysis of americium in non-separated spent fuels using high resolution ICP-OES and sector field ICP-MS 
Cite this: J. Anal. At. Spectrom., 2014, 29,817

Received 17th February 2014 Accepted 13th March 2014

DOI: $10.1039 / c 4 j a 00068 d$

www.rsc.org/jaas

\section{Elemental and isotopic analysis of americium in non-separated spent fuels using high resolution ICP-OES and sector field ICP-MS}

\author{
Michael Krachler,* Rafael Alvarez-Sarandes and Stefaan Van Winckel
}

As there are no matrix-matched certified reference materials, accurate and straightforward analytical procedures for the determination of americium (Am) in non-separated spent fuels employing high resolution ICP-OES and sector field (SF-) ICP-MS were developed and cross-validated. One spent $(\mathrm{Th}, \mathrm{Pu}) \mathrm{O}_{2}$ fuel and two U/Pu-based spent fuels representing different chemical and isotopic compositions were analysed for their Am content. Even though the lowest limit of detection $(0.07 \mu \mathrm{g}$ $\mathrm{kg}^{-1}$ ) was obtained at $\lambda=283.226 \mathrm{~nm}$, the ICP-OES signal at $\lambda=408.929 \mathrm{~nm}$ provided the most accurate results for the analysis of the spent fuel among the six investigated Am emission wavelengths. Massive spectral interference from Th precluded the use of the $\lambda=283.226 \mathrm{~nm}$ emission line for Am analysis of the $(\mathrm{Th}, \mathrm{Pu}) \mathrm{O}_{2}$ fuel, while other potential interferences from plutonium ( $\mathrm{Pu}$ ) and neptunium (Np) could be excluded for all the tested Am wavelengths. Employing ICP-OES, both external calibration and standard addition yielded comparable Am amount concentrations. Calibration of the SF-ICP-MS response for Am was accomplished using both ${ }^{232} \mathrm{Th}$ and ${ }^{238} \mathrm{U}$ signals as well as applying the related mass bias. This calibration methodology that is frequently used in the absence of an Am stock standard solution was tested against a home-made ${ }^{241} \mathrm{Am}$ stock standard solution underlining the validity of this calibration approach. Sector field ICP-MS analysis essentially confirmed the Am concentrations obtained using ICP-OES in the three spent fuel solutions with mean values overlapping within their standard deviations. Considering isotopes of other actinides such as $\mathrm{Pu}$ and curium $(\mathrm{Cm})$, the Am isotopic abundance $\left({ }^{241} \mathrm{Am},{ }^{242} \mathrm{Am},{ }^{243} \mathrm{Am}\right)$ was established in two non-separated fuel solutions comparing well with model calculations based on the ORIGEN-2 code.

\section{Introduction}

The use of mixed oxide (MOX) nuclear fuels such as thoriabased $(\mathrm{Th}, \mathrm{Pu}) \mathrm{O}_{2}$ fuels or $\mathrm{U} / \mathrm{Pu}$ fuels in light water reactors produces sizeable amounts of the artificial element americium (Am). While the Am isotopes ${ }^{241} \mathrm{Am}\left(t_{1 / 2}=432.2\right.$ years $)$ and ${ }^{243} \mathrm{Am}\left(t_{1 / 2}=7370\right.$ years $)$ are predominantly produced through $\beta$-decay of $\mathrm{Pu}$, minor amounts of ${ }^{242} \mathrm{Am}\left(t_{1 / 2}=37420\right.$ years $)$ are also generated. ${ }^{1}$ Therefore, the analysis of Am is included in the characterisation of spent nuclear fuels.

From an analytical perspective, $\alpha$ - and $\gamma$-spectrometry as well as ICP-OES and ICP-MS are employed frequently for this purpose. Among the four analytical techniques mentioned above, ICP-OES is the least used, even though suitable Am emission wavelengths that provide selectivity and sufficient sensitivity have been identified..$^{2-5}$

European Commission - Joint Research Centre, Institute for Transuranium Elements, ITU, P.O. Box 2340, D-76125 Karlsruhe, Germany. E-mail: michael.krachler@ec. europa.eu; Web: http://itu.jrc.ec.europa.eu; Fax: +497247951 588; Tel: +49 7247 951884
One of the commonly raised concerns associated with the analysis of radioactive samples is related to the quality assurance of such an analysis due to the lack of suitable certified reference materials. Matrix-matched reference materials are commonly available for conventional, i.e., non-radioactive elemental and isotopic analyses. Despite the recognised need for additional radio-analytical certified reference materials, ${ }^{6}$ these quality control standards are frequently not accessible when an irradiated material is to be analysed. This aspect becomes even more complicated by the fact that isotopically pure, certified stock standard solutions of actinides are often not available and/or quite costly. Similarly, the transport of radioactive samples to another laboratory for complementary analysis is largely limited due to security and safety issues as well as the expenses for such an endeavour.

In the light of the above mentioned constraints it is highly desirable to develop techniques for complementary analysis on the spot where the irradiated sample is handled for supplementary scientific investigations. ${ }^{7,8}$ At JRC-ITU, sector field ICPMS (SF-ICP-MS) is employed routinely for Am analysis of irradiated samples. Because most spent nuclear fuels contain also considerable amounts of $\mathrm{Pu}$ (Table 1), however, the 
Table 1 Major actinides in the three investigated spent nuclear fuels as determined using sector field ICP-MS. Concentrations refer to the total amount of the specific element, i.e. the sum of all individual isotopes of that element at the time of analysis ${ }^{b}$

\begin{tabular}{lccl}
\hline Spent fuel & $\mathrm{U}$, mass $\%$ & $\mathrm{Pu}$, mass $\%$ & Th, mass\% \\
\hline MET 1-4 & 63.9 & 19.5 & $-^{a}$ \\
MET 1-7 & 61.4 & 15.1 & $-{ }^{a}$ \\
$(\mathrm{Th}, \mathrm{Pu}) \mathrm{O}_{2}$ & 1.69 & 0.56 & 83.2
\end{tabular}

${ }^{a}$ Not determined, but $<0.1 \%$. ${ }^{b}$ Note that the mass fractions of $\mathrm{U}, \mathrm{Pu}$, and Th represent $\sim 76.5$ to $85.5 \%$ of the total inventory only. The two metallic fuels additionally contain $\sim 9 \% \mathrm{Zr}, \sim 3-4 \%$ lanthanides, $\sim 1.8-$ $3.6 \%$ minor actinides and $\sim 1 \%$ Mo (see text for details). The major residual contributor to the $(\mathrm{Th}, \mathrm{Pu}) \mathrm{O}_{2}$ fuel inventory is oxygen amounting to $\sim 12 \%$.

reliability of the ICP-MS ${ }^{241} \mathrm{Am}$ data is hampered by the presence of ${ }^{241} \mathrm{Pu}$ in the analyte solution and is only possible after a chemical separation of both elements from each other. While even SF-ICP-MS cannot distinguish between $\mathrm{Am}$ and $\mathrm{Pu}$ at $\mathrm{m} / \mathrm{z}$ 241 in the mass spectrum, ICP-OES can, because both the elements emit light at different wavelengths. Moreover, none of the sensitive Am emission wavelengths is overlapped by any $\mathrm{Pu}$ signal, thus providing the potential for the direct determination of Am in the spent nuclear fuel. ${ }^{5}$ Hence ICP-MS and ICP-OES, employing diverse physical detection principles, complement each other and thereby help to improve the quality of Am analysis in a nuclear fuel. ${ }^{7,8}$

Building on our previous experience, ${ }^{5}$ the current comparative study aims to investigate the potential and pitfalls of both ICP-OES and ICP-MS for the direct Am analysis of the "nonseparated" spent fuel. Various experimental approaches including the application of external calibration against a home-made ${ }^{241} \mathrm{Am}$ (via separation of ${ }^{241} \mathrm{Am}$ from a concentrated Pu solution) or a commercial ${ }^{238} \mathrm{U}$ standard, as well as standard addition have been investigated to establish the Am concentration in three selected nuclear fuels. Moreover, the isotopic composition of Am $\left({ }^{241} \mathrm{Am},{ }^{242} \mathrm{Am}\right.$, and $\left.{ }^{243} \mathrm{Am}\right)$ has been determined using SF-ICP-MS with the obtained experimental results compared to predictive model calculations.

\section{Experimental}

\section{Instrumentation}

The sample introduction system of the ICP-OES and SF-ICP-MS instruments has been installed in a glove box to allow the analysis of radioactive samples. This complex modification of the original instrumental design was necessary to protect the analyst from $\alpha$ and $\beta$ radiation originating from the radioactive sample solutions.

All ICP-OES measurements were carried out with a nuclearised high resolution ICP-OES instrument (Ultima2, HORIBA Jobin Yvon, Longjumeau, France). The sample introduction system consisted of a PolyPro ST nebulizer (Elemental Scientific (ESI), Inc., Omaha, NE, USA), pumped at a sample uptake rate of

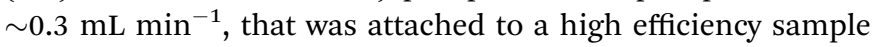
introduction system (Apex E, ESI). Measurements were recorded either at the maximum of the individual Am emission signals (Max mode) for eight seconds or by using nine measurement points $(1 s$ each) centred around the peak maximum (Gauss mode). For the latter option, the ICP-OES software calculates a Gaussian function using the nine acquired data points. To obtain net peak intensities, the spectral background around the vicinity of each Am signal was monitored for four seconds and subsequently subtracted from the Am signals.

Sector field ICP-MS measurements were carried out with a nuclearised Element2 instrument (Thermo Scientific, Bremen, Germany). The sample introduction system consisted of a selfaspirating micro-flow PFA-100 nebulizer (ESI) and a cyclonic spray-chamber (Glass Expansion, West Melbourne Vic, Australia). The RF generator was operated at $1250 \mathrm{~W}$ and the Ar gas flows were set to $16 \mathrm{~L} \mathrm{~min}^{-1}$ for the plasma gas, $0.9 \mathrm{~L} \mathrm{~min}^{-1}$ for the auxiliary gas and $0.9-1.1 \mathrm{~L} \mathrm{~min}^{-1}$ for the sample gas (daily optimised), respectively.

The ICP-MS Am measurements were part of overview analyses of dissolved nuclear fuel samples. The employed analytical method covered the main mass ranges for transition metals $(\mathrm{m} /$ $z$ 50-67), fission products $(\mathrm{m} / z$ 85-165) and actinides $(\mathrm{m} / z 232-$ 248 ) in the low resolution (LR) mode followed by measurements of the transition metals and actinides in the medium resolution (MR) mode for identifying potential spectral interferents across these mass ranges. For each analysis, the peak areas of seven spectra were averaged and each blank/standard/sample was measured three times consecutively. For quantification, external calibrations were performed before and repeated after the blank/sample measurements.

\section{Reagents and samples}

Because of their radioactive nature, all Am standard solutions as well as nuclear fuel samples had to be handled in glove boxes and chemical hot cells, respectively. For the preparation of all the solutions high purity water $(18.2 \mathrm{M} \Omega \mathrm{cm})$ from a MilliQ (Millipore) water purification system and sub-boiled nitric acid were used. The employed ${ }^{241} \mathrm{Am}$ stock solution was obtained from a Pu stock solution $\left(115 \mathrm{~g} \mathrm{~L} \mathrm{~L}^{-1}\right)$ in which ${ }^{241} \mathrm{Am}$ was "produced" from the decay of ${ }^{241} \mathrm{Pu} .{ }^{5}$ Before use, ${ }^{241} \mathrm{Am}$ present in this stock solution was separated from ${ }^{241} \mathrm{Pu}$ via a combination of liquid extraction and extraction chromatography. ${ }^{5}$ Subsequently, the Am concentration (1550 mg kg-1) and isotopic purity of this stock standard solution were assessed using both $\alpha$ - and $\gamma$-spectrometry. ${ }^{9}$

External calibration solutions for ICP-OES were prepared in $0.14 \mathrm{M}$ nitric acid and consisted of $0,2,5,10,20,50$, and $100 \mu \mathrm{g}$ $\mathrm{kg}^{-1}$ of ${ }^{241} \mathrm{Am}$. For standard addition experiments, the dissolved spent fuel samples were spiked gravimetrically at three concentration levels yielding ${ }^{241} \mathrm{Am}$ additions of nominal 10, 20 and $30 \mu \mathrm{g} \mathrm{kg}^{-1}$ in the actual measurement solutions.

External calibration was also applied for the SF-ICP-MS overview analyses, by measuring mixed elemental standard solutions (Multi-element Calibration Standard solutions from PerkinElmer Environmental Health, Shelton, Connecticut, USA) containing 68 elements in total covering the mass range of interest. Each calibration series consisted of a standard blank 
solution and five calibration standards at elemental concentrations of respectively $0.2,0.6,1,5$ and $20 \mu \mathrm{g} \mathrm{kg}^{-1}$ in $1 \mathrm{M} \mathrm{HNO}_{3}$. "Internal standards" (1 $\mu \mathrm{g} \mathrm{kg}^{-1}$ of each Co, In, Ho and Th) were added to all the calibration solutions and the samples in order to follow (and correct for) the drift in instrumental sensitivity during the measurement sequence.

\section{Spent fuel samples}

A two mm slice of an irradiated ( $\mathrm{Th}, \mathrm{Pu}) \mathrm{O}_{2}$ fuel rod was dissolved by boiling under reflux in a so-called "Thorex solution" containing $\mathrm{Al}\left(\mathrm{NO}_{3}\right)_{3} \cdot 9 \mathrm{H}_{2} \mathrm{O}, \mathrm{NaF}$ and $14.4 \mathrm{M} \mathrm{HNO}_{3}$ in a chemical hot-cell at JRC-ITU using telemanipulators. The Am content of this dissolved $(\mathrm{Th}, \mathrm{Pu}) \mathrm{O}_{2}$ fuel sample has been determined previously in the framework of the LWR-Deputy Project. ${ }^{10}$ Gamma emissions from the decay of ${ }^{241} \mathrm{Am}$ were measured employing $\gamma$-spectrometry without any chemical separation of the actinide from the spent fuel matrix. The detector of the $\gamma$-spectrometer was calibrated using a mixed radionuclide $\gamma$ standard. The ${ }^{241} \mathrm{Am}$ result obtained from $\gamma$-spectrometry was combined with the ${ }^{241} \mathrm{Am} /{ }^{243} \mathrm{Am}$ ratio as measured using SFICP-MS in a separated fraction of the investigated fuel sample to obtain the concentration of ${ }^{243} \mathrm{Am}$. The ${ }^{242} \mathrm{Am}$ contents in this sample were below the detection limit of SF-ICP-MS. The dissolved fuel solution was further diluted $\sim 200$-times with $0.14 \mathrm{M}$ nitric acid for subsequent ICP-OES analysis.

Similarly, two spent metallic fuels (MET 1-4 and MET 1-7) with different elemental compositions (Table 1) have been dissolved and investigated for Am. Both experimental research fuels have been doped with rare earth elements (REE) and minor actinides (MA, amongst which is Am) in order to study the impact of irradiation on these elements within the METAPHIX-1 Project. ${ }^{11}$ Sample MET 1-4 was doped with 2\% REE and 2\% MA, sample MET 1-7 with 5\% REE and 5\% MA. ${ }^{11}$ The dissolution of the fuel samples was carried out by boiling under reflux in a mixture of $3 \mathrm{M} \mathrm{HNO}_{3}$ and $0.2 \mathrm{M} \mathrm{HF}$ in a chemical hot-cell at JRC-ITU. From these dissolved fuel solutions, further dilutions have been prepared with $0.14 \mathrm{M} \mathrm{HNO}_{3}$ and $1 \mathrm{M} \mathrm{HNO}_{3}$ for ICP-OES and SF-ICP-MS analyses, respectively. The final dilution factors ranged from $\sim 500$ to $\sim 1700$ for ICP-OES analyses depending on the actual Am concentration, and amounted to $~ 9000$ for measurements employing SF-ICP-MS. As all sample dilutions were performed on a weight basis using a calibrated balance, the impact of the various dilution steps on the accuracy of the results is expected to be negligible.

\section{Results and discussion}

\section{Selection of data acquisition parameters for ICP-OES}

Based on our recent investigation on the performance of ICPOES measurement techniques for $\mathrm{Am},{ }^{5}$ the following six most promising Am emission wavelengths, namely $\lambda=283.226 \mathrm{~nm}, \lambda$ $=292.059 \mathrm{~nm}, \lambda=392.625 \mathrm{~nm}, \lambda=408.929 \mathrm{~nm}, \lambda=450.945$ $\mathrm{nm}$, and $\lambda=469.970 \mathrm{~nm}$, were considered for the current study. The absence of significant spectral interferences and/or low Am detection limits (LOD) was the main reason for choosing these
Am emission wavelengths for further in-depth inspections for quantification of Am in the spent fuel. ${ }^{5}$

At $\lambda=283.226 \mathrm{~nm}$ for example, a LOD for Am as low as $0.07 \mu \mathrm{g} \mathrm{kg}{ }^{-1}$ has been reported recently for aqueous standard solutions. ${ }^{5}$ Because this most sensitive Am emission line might be potentially compromised by interference from $\mathrm{U}$ and $\mathrm{Th}$, its potential for spent fuel analysis remains to be proven. ${ }^{4,5}$ Other emission wavelengths, even though slightly less sensitive, still provide Am LODs at sub- $\mu \mathrm{g} \mathrm{kg}{ }^{-1}$ or low $\mu \mathrm{g} \mathrm{kg}{ }^{-1}$ concentration levels. ${ }^{5}$

The splitting of a single emission line into several lines, each of which corresponds to an individual isotope of this particular element, is referred to as isotopic shift. Similar to other heavy elements such as Pu and U, ${ }^{\mathbf{1 2}-16}$ ICP-OES measurements of Am are also affected by this phenomenon. ${ }^{5}$ In this context it is important to point out here that usually ICP-OES measurements are carried out at the peak top only (just like ICP-MS measurements) to achieve the best possible counting statistics within a given data acquisition time. As the Am inventory of spent nuclear fuel samples consists of mainly ${ }^{241} \mathrm{Am}$ and ${ }^{243} \mathrm{Am}-$ besides minor contributions from ${ }^{242} \mathrm{Am}$ - in different proportions, the position of the actual Am ICP-OES signal might be shifted slightly in the wavelength spectrum compared to a mono-isotopic Am standard solution that might have been used for wavelength calibration. While the isotopic shift is $<4 \mathrm{pm}$ at most for ${ }^{241} \mathrm{Am}$ and ${ }^{243} \mathrm{Am},{ }^{5}$ this small difference in the wavelength position of the peak top of different Am isotopes may still lead to inaccurate results when considering the calibrated wavelength position of the ${ }^{241} \mathrm{Am}$ emission signal. In other words, while employing the so-called "Max measurement mode", the actual peak top may be missed by 1 or $2 \mathrm{pm}$, leading to deteriorated results. Unlike the substantial distance between individual $\mathrm{U}$ isotopes in the emission spectrum, ${ }^{\mathbf{1 3 - 1 5}}$ the minor pronounced isotopic shift of Am, however, does not allow for a direct isotopic analysis of Am using ICP-OES. ${ }^{5}$

To investigate the potential negative impact of the Max mode on the accuracy of the actual results, all ICP-OES measurements have been also carried out concurrently using the Gauss mode. The idea behind this experimental approach is that acquiring several measurement points in small increments $(0.5-2 \mathrm{pm}$, depending on the peak width of the ICP-OES signal) around the theoretical peak position of the mono-isotopic ${ }^{241} \mathrm{Am}$ calibration standard followed by calculating a Gauss function using these experimental data will compensate for the slight shift in the position of the Am ICP-OES signal obtained from an actual fuel sample that contains both ${ }^{241} \mathrm{Am}$ and ${ }^{243} \mathrm{Am}$.

\section{ICP-OES analysis of Am in spent nuclear fuels}

ICP-OES emission spectra - qualitative assessment. Considering the ICP-OES analysis of radio-active samples, the emission spectra of actinides are frequently more complex compared to those of other "conventional" elements. While sensitive emission lines providing single, symmetric, confined signals lacking spectral overlaps as well as the corresponding smooth spectral backgrounds have been readily identified for elements such as $\mathrm{K}, \mathrm{Li}, \mathrm{Na}$, and $\mathrm{Nd},{ }^{7,8}$ for example, the 
unambiguous quantification of the line-rich Am spectra is hampered by severe spectral overlaps from other major constituents in non-separated fuel solutions such as $\mathrm{U}$ and $\mathrm{Th}$ (Fig. 1). In addition to the occurrence of isotopic shift, the presence of noisy spectral baselines and multiplets, i.e. multiple peaks for a single element/isotope, demands a careful selection of measurement and evaluation parameters for obtaining reliable Am results.

The above mentioned key aspects are highlighted graphically in more detail in Fig. 1 for the four most promising wavelength regions of Am. In this figure the emission spectrum of a $110 \mu \mathrm{g}$ $\mathrm{kg}^{-1241} \mathrm{Am}$ standard solution (black squares) is superimposed on the spectra of the three investigated spent fuels at all four different wavelength regions. One should take into account, however, that Th-based fuels still remain a minority with the vast majority of nuclear fuels employed currently being based on $\mathrm{U} / \mathrm{Pu}$ oxides. In other words, the obvious analytical difficulties due to the presence of excessive amounts of Th in one of the investigated fuels during ICP-OES Am analysis are more an exception than the rule. Taken together, however, the irradiated fuel samples considered in this study represent a distinct variety of potential spent fuel compositions.

Even though the metallic fuel solutions MET 1-4 and MET 17 have similar $\mathrm{U}$ and $\mathrm{Pu}$ concentrations (Table 1), one must consider that the latter was almost 4-times more diluted for ICPOES analysis when comparing visually the spectra presented in Fig. 1. As regards non-identified peaks in these emission spectra, apparent spectral interferences from neptunium (Np), another transuranium element mainly present as ${ }^{237} \mathrm{~Np}$ at comparable concentrations in the spent fuel, were excluded experimentally (data not shown).

In the wavelength region centred around $\lambda=283.226 \mathrm{~nm}$ massive Th interference at $\lambda=283.231 \mathrm{~nm}$ overlaps entirely with the Am signal and, as such, excludes the use of this emission line for Am analysis of Th-based fuels. This essential fact was addressed only partly in earlier studies. ${ }^{2-4}$ But also in the case of the two investigated metallic U/Pu fuels (Table 1), the obvious presence of a substantial U signal at $\lambda=283.206 \mathrm{~nm}$,
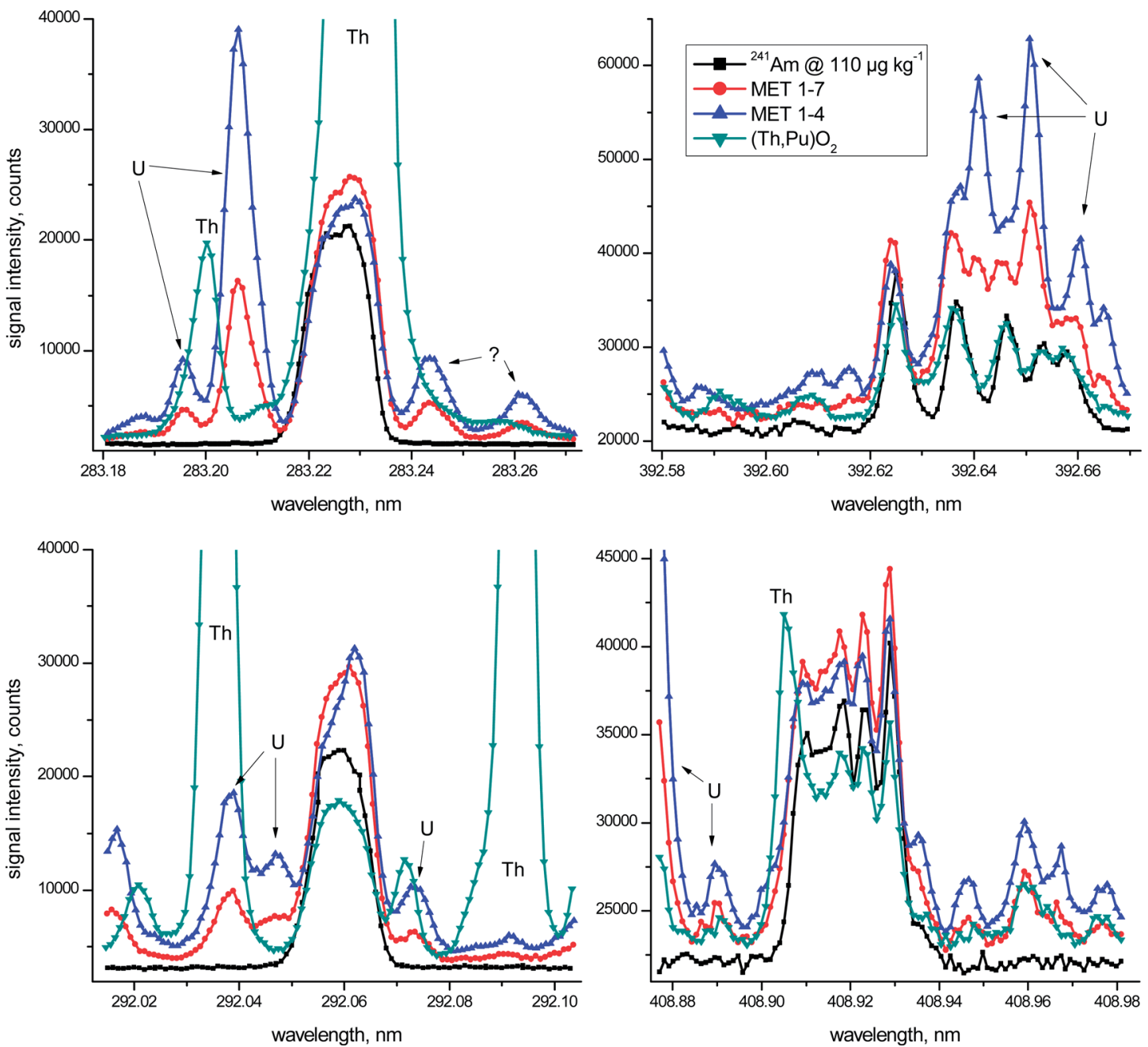

Fig. 1 High resolution ICP-OES spectra of the two spent metallic U/Pu fuels, one (Th, Pu) $\mathrm{O}_{2}$ fuel and a $110 \mu \mathrm{g} \mathrm{kg}{ }^{-1} 241 \mathrm{Am}$ standard solution for comparison. Each of the 101 measurement points was recorded for one second using spectral increments of 0.5 pm. The displayed graphs centred at $\lambda=283.226 \mathrm{~nm}, \lambda=292.059 \mathrm{~nm}, \lambda=392.625 \mathrm{~nm}$, and $\lambda=408.929 \mathrm{~nm}$ represent a spectral window of 100 pm highlighting both the Am signals and spectral interference evident for the investigated fuel samples. 
even though as much as $20 \mathrm{pm}$ off to the left of the Am peak maximum, may slightly increase the calculated Am concentration (Fig. 1). It is only due to the high resolution capabilities of the employed ICP-OES instrument, providing a spectral resolution of $<5 \mathrm{pm}$ in this wavelength region, which allows the consideration of this Am emission line for quantification, even in the presence of large amounts of $U$. The origin of the two minor peaks in both MET spectra on the right hand side of the Am signal is unclear at the moment. While a Fe signal at $\lambda=$ $283.244 \mathrm{~nm}$ is suggested by the ICP-OES software for one of these peaks, note that Fe is present in both MET fuels in almost identical concentrations and the corresponding spectra do not support these peaks as originating from Fe. Additional experimental investigations also excluded $\mathrm{Pu}$ - another major constituent of the MET fuels (Table 1) - as a potential candidate for the occurrence of these two peaks.

Similarly, spectral interference from both Th (in the case of the Th-based fuel) and U (for both MET fuels) hampers the reliable determination of Am at $\lambda=292.059 \mathrm{~nm}$ (Fig. 1). While the peaks centred around $\lambda=292.073 \mathrm{~nm}$ were identified as $\mathrm{U}$ signals, the origin of the nearby peak at $\lambda=292.071 \mathrm{~nm}$ related to the $(\mathrm{Th}, \mathrm{Pu}) \mathrm{O}_{2}$ fuel is not evident at present.

The Am spectra in the vicinity of both $\lambda=392.625 \mathrm{~nm}$ and $\lambda$ $=408.929 \mathrm{~nm}$ are characterised by multiplets consisting of five noticeable peaks each. ${ }^{5}$ The main difference between these two Am wavelength regions is the fact that the highest peak is positioned either at the outermost left $(\lambda=392.625 \mathrm{~nm})$ or the outermost right side $(\lambda=408.929 \mathrm{~nm})$ of the corresponding Am multiplet (Fig. 1). Even though certain distinct spectral overlaps from $\mathrm{U}(\lambda=392.625 \mathrm{~nm})$ and $\mathrm{Th}(\lambda=408.929 \mathrm{~nm})$ are evident in the emission spectra of the fuel samples, the major signal of each of the multiplets appears largely unaffected by this spectral interference (Fig. 1). Therefore only these highest Am peaks were examined further in more detail for quantification purposes.

ICP-OES measurement modes and calibration strategies quantitative assessment. The analytical method presented here focused systematically on the potential impact of the above mentioned spectral overlaps on the quality of the Am data. Additionally, the influence of various calibration approaches and data acquisition modes was explored in more detail. To this end, the three spent fuel samples have been analysed repeatedly at six emission wavelengths using both the Gauss mode and the Max mode (Table 2). The quantification of Am in the spent fuel solutions was based either on external calibration or on standard addition (Table 2).

Besides the four emission wavelengths considered in Fig. 1, two additional Am wavelengths, namely $\lambda=450.945 \mathrm{~nm}$ and $\lambda=$ $469.970 \mathrm{~nm}$, were included in this assessment. While these two additional Am emission lines might provide a reasonable opportunity for Am analysis, ${ }^{5}$ they, however, did not provide sufficiently low detection limits to be fully exploited in the current study. This fact is reflected by the generally poorer analytical performance obtained at these two Am emission lines resulting in increased standard deviations of their respective mean values (Table 2). To avoid an unnecessarily high radiation dose originating from the radioactive fuel samples reaching the operator of the ICP-OES, more concentrated samples were not

Table 2 Concentration and standard deviation $\left[\mu \mathrm{g} \mathrm{kg}^{-1}\right]$ of Am in three investigated spent nuclear fuel solutions as determined using ICP-OES at six emission wavelengths applying external calibration $(N=3)$ and standard addition $(N=4)$

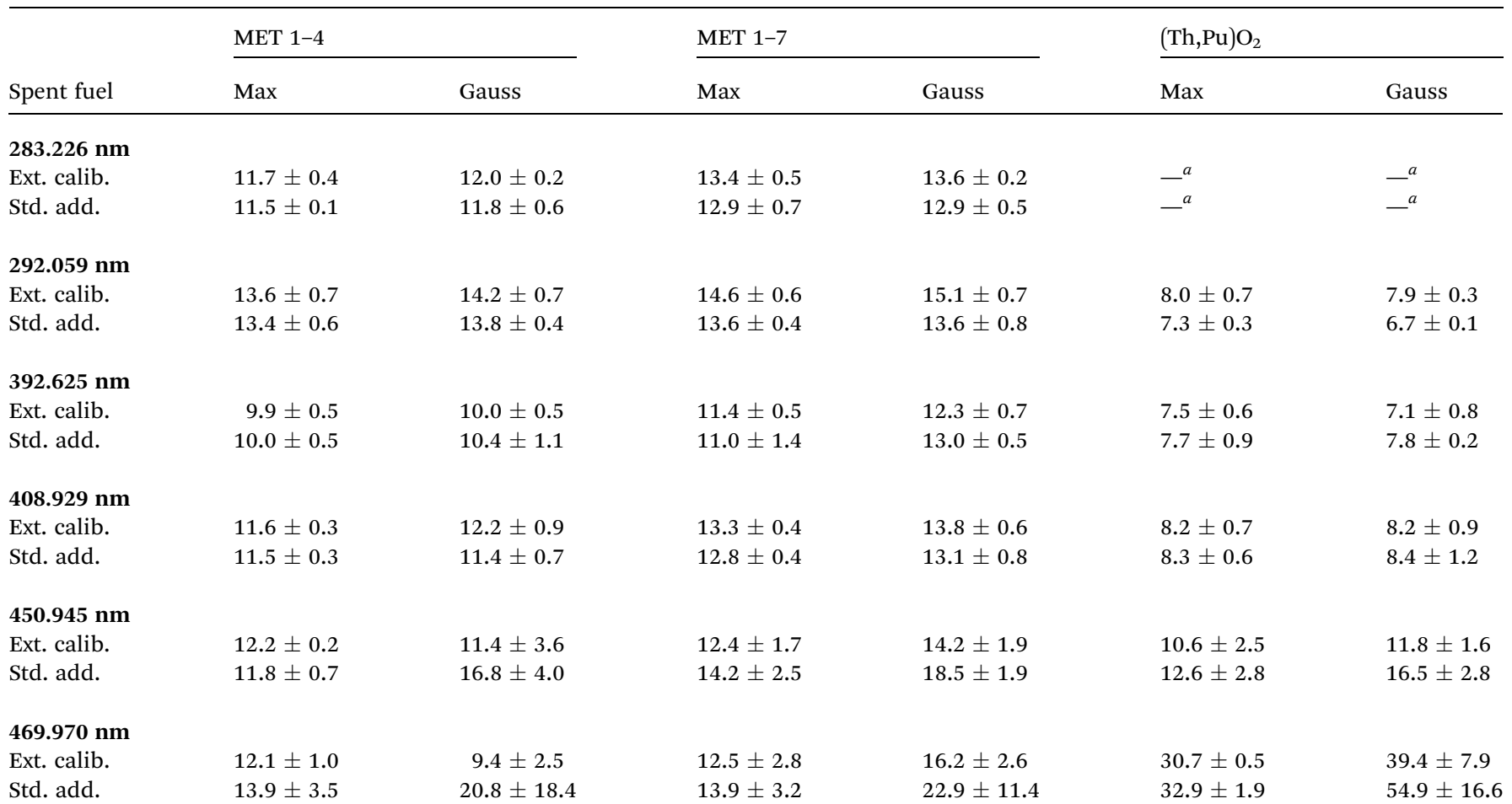

${ }^{a}$ Not determined due to massive spectral interference from Th. Please see text for details. 
considered here. Thus, these two Am wavelengths were omitted for further in-depth inspections and are included in Table 2 for the sake of completeness only.

Standard addition experiments always consisted of the analyses of the spent fuel solution plus three aliquots that were additionally spiked with ${ }^{241} \mathrm{Am}$ at increasing concentration levels. The corresponding linear regression lines for two of the investigated fuels are shown in Fig. 2 for the emission line centred around $\lambda=408.929 \mathrm{~nm}$. The high correlation coefficient and almost identical slopes of the two regression lines highlight the favourable analytical performance of this experimental approach.

Generally speaking, there was no obvious systematic difference identifiable between the Am results obtained from the diverse quantification approaches, neither between Max mode and Gauss mode nor between external calibration and standard addition (Table 2). This satisfactory finding, that holds true for all three investigated fuels, has two important implications: first, potential matrix effects have no measurable impact on the accuracy of the Am results allowing the application of conventional external calibration for quantification purposes. Consequently, there is no need to use the standard addition calibration approach, which is distinctly more laborious and additionally increases the exposure time of the analyst to the investigated radioactive samples. Second, the impact of the Am isotopic shift is negligible for the selected wavelengths signifying that the various Am isotopic compositions of the investigated fuel samples will not measurably decrease the accuracy of the Am results when employing the Max mode. As such, the Max mode is the preferred data acquisition mode making efficient use of the measurement time by providing the best possible counting statistics.

Despite the above mentioned reasonable agreement of Am results within a single emission wavelength, systematic differences were nonetheless observed between individual

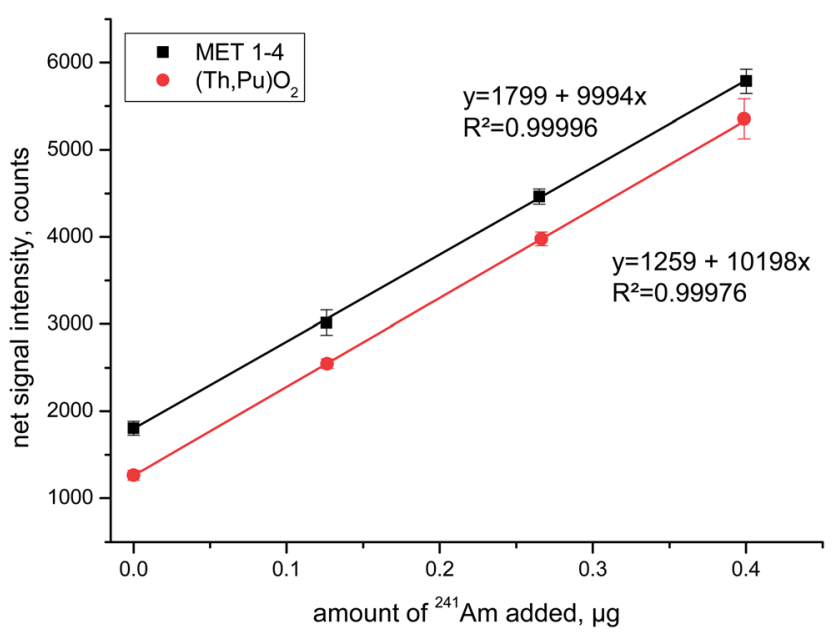

Fig. 2 Representative linear regression curves of standard addition experiments for two selected spent fuel solutions that were spiked with ${ }^{241} \mathrm{Am}$ at three different concentration levels. Data displayed summarize the replicate ICP-OES Am measurements at $\lambda=$ $408.929 \mathrm{~nm}$ using the Max mode on four consecutive days. wavelengths (Table 2). While the Am concentrations obtained at $\lambda=283.226 \mathrm{~nm}$ and $\lambda=408.929 \mathrm{~nm}$ were consistent, approximately $15 \%$ lower and higher results were calculated systematically from the emission signals at $\lambda=292.059 \mathrm{~nm}$ and $\lambda=$ $392.625 \mathrm{~nm}$, respectively (Table 2). In this context, a comparison to another analytical technique would be most advantageous to help identify the most accurate Am concentration values. Such an independent assessment of the ICP-OES accuracy employing sector field ICP-MS, based on a different physical detection principle, underlines the quality assurance of the analytical results. ${ }^{7,8}$ Consequently, without a suitable matrix-matched certified reference material, the obtained ICP-OES Am concentration values were compared to the in-house sector field ICPMS data as described in detail below.

\section{Sector field ICP-MS}

Calibration strategies. The calibration of the ICP-MS response for all actinides in overview analyses is somewhat tricky as only $\mathrm{Th}$ and $\mathrm{U}$ are present in the calibration standard solutions (Th in all blanks, standards, samples as internal standard). The isotopic composition of $\mathrm{U}$ is never certified in commercial multi-element calibration solutions so that in practice only ${ }^{238} \mathrm{U}$ can be used for calibration of the uranium ICP-MS response. As a first approach, the signal intensities of other adjacent actinides like $\mathrm{Np}, \mathrm{Pu}, \mathrm{Am}$ and $\mathrm{Cm}$ can be calibrated using ${ }^{238} \mathrm{U}$. This attempt presumes, however, the same (or at least very similar) elemental sensitivity for all actinides which is an acceptable assumption based on the comparable first ionisation potentials of the actinides.

Nevertheless, the accuracy of the calibration strategy can be improved by also taking the mass bias (instrumental mass discrimination) effects into account. As no certified isotopic reference material was measured, the correction for the mass bias was estimated based on the sensitivity difference between the internal standard ${ }^{232} \mathrm{Th}$ and ${ }^{238} \mathrm{U}$ (as if both nuclides were isotopes of the same actinide, An), again presuming the same elemental sensitivity for all actinides.

In addition, the different oxide formation rates of $\mathrm{Th}$ and $\mathrm{U}$ were also considered for the determination of the mass bias by also measuring $m / z \quad 248\left({ }^{232} \mathrm{ThO}^{+}\right)$and $m / z \quad 254\left({ }^{238} \mathrm{UO}^{+}\right)$. Depending on plasma conditions, the oxide formation rate of $\mathrm{Th}$ and $\mathrm{U}$ may differ by up to an order of magnitude because of the diverse strength of their oxide bonds. This can have repercussions on the apparent sensitivity of both elements. To compensate for this deteriorating effect the calculated mass bias was based on the sensitivity difference between ${ }^{232} \mathrm{Th}+$ ${ }^{232}$ ThO' $v s .{ }^{238} \mathrm{U}+{ }^{238} \mathrm{UO}$ '. While a linear, power or exponential law function was used for the assessment of the mass bias, comparable values were obtained within the measurement uncertainties realistic for overview analyses. For the results reported in this study, an exponential law function for the mass bias correction factor has been used.

Measurement of the ${ }^{241} \mathrm{Am}$ standard solution. In order to validate the above mentioned experimental approach, an ${ }^{241} \mathrm{Am}$ standard solution was prepared from the same ${ }^{241} \mathrm{Am}$ stock solution described before, at a concentration level of $5 \mu \mathrm{g} \mathrm{kg}{ }^{-1}$, 
containing the same mix of internal standards. This ${ }^{241} \mathrm{Am}$ standard solution was measured repeatedly during the analysis sequence as a "sample" before $(N=3)$ and after $(N=3)$ the dissolved fuel samples. When calibrating the ICP-MS response only with ${ }^{238} \mathrm{U}$, the low resolution (LR) ${ }^{241} \mathrm{Am}$ results were $7.8 \%$ higher than the reference value - assessed in-house using $\gamma$-spectrometry - of the standard solution. In medium resolution (MR), ${ }^{241} \mathrm{Am}$ results were $16.6 \%$ higher than the reference value. This discrepancy reveals evidently the limitations of the above experimental approach.

After mass bias correction via the ${ }^{232} \mathrm{Th}$ and ${ }^{238} \mathrm{U}$ measurements (including their corresponding oxides), however, the obtained Am concentration in LR and MR confirmed each other effectively with recoveries of $105.6 \%$ and $105.4 \%$, respectively. These results are perfectly acceptable for overview analyses along with external calibration and proved the validity of this applied methodology. The relative standard deviations for the six replicate measurements were $1.8 \%$ and $3.3 \%$ for the LR and MR results, respectively.

Measurement of Am in spent fuel solutions. When measuring dissolved spent fuel in an ICP-MS overview analysis without any prior chemical separation, the Am spectrum suffers from serious isobaric interference (Fig. 3). The ICP-MS signal at $m / z$ 241, for example, signifies the sum of ${ }^{241} \mathrm{Pu}$ and ${ }^{241} \mathrm{Am}$. While the peak at $m / z 242$ represents the sum of ${ }^{242} \mathrm{Pu},{ }^{242} \mathrm{Am}$ and ${ }^{242} \mathrm{Cm}$, individual contributions of ${ }^{243} \mathrm{Am}$ and ${ }^{243} \mathrm{Cm}$ are summed up at $m / z 243$ (Fig. 3). As a consequence, supplementary information is needed in order to retrieve useful information from the ICP-MS analysis of the spent fuel.

To this end, knowing the initial nuclear fuel composition and the irradiation history, ORIGEN-2 calculations (a computer code system for calculating the buildup, decay, and processing of radioactive materials) ${ }^{\mathbf{1 7}}$ were performed to establish the spent fuel composition after irradiation. Additional ${ }^{241} \mathrm{Pu}$ decay calculations were performed to consider the time lapse between

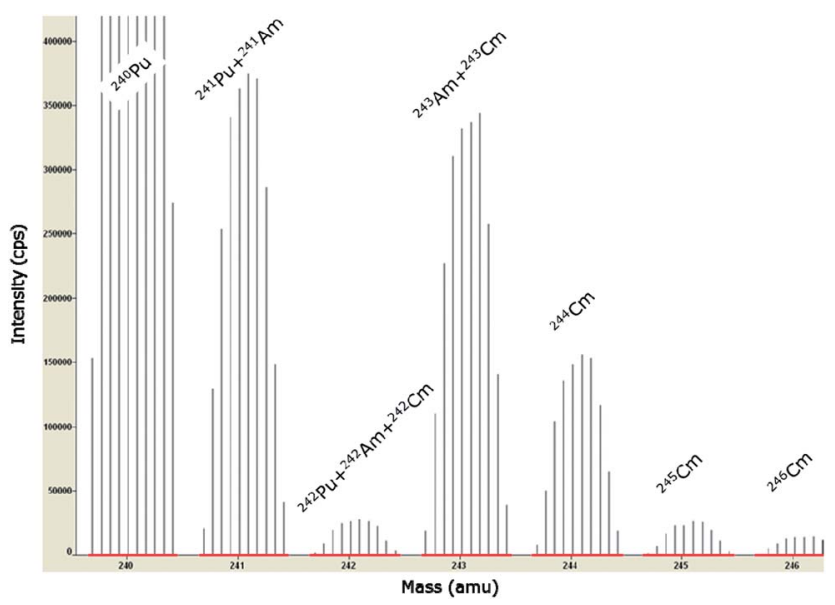

Fig. 3 Minor actinide spectrum from $\mathrm{m} / \mathrm{z} 240$ to $\mathrm{m} / \mathrm{z} 246$ of a representative spent fuel sample (MET 1-4) as measured in an overview analysis employing SF-ICP-MS. Isobaric spectral overlaps from various $\mathrm{Cm}$ and $\mathrm{Pu}$ isotopes on the Am isotopes at $\mathrm{m} / \mathrm{z} 241,242$, and 243 show the difficulties of extracting worthwhile information from the mass spectrum. See text for further details. the end of irradiation and the day of measurement, as ${ }^{241} \mathrm{Pu}$ decays to ${ }^{241} \mathrm{Am}$. Other decay corrections were not considered necessary as the half-lives of all other nuclides of concern are substantially longer. Only the relative information (e.g. ${ }^{241} \mathrm{Am} /{ }^{241} \mathrm{Pu}$ or ${ }^{243} \mathrm{Am} /{ }^{243} \mathrm{Cm}$ ratio) of the ORIGEN-2 calculations was used to resolve the mass spectrum into the different nuclides.

These corrections were almost negligible for ${ }^{243} \mathrm{Am}$ as the spectral overlap caused by ${ }^{243} \mathrm{Cm}$ was $<0.3 \%$. For ${ }^{242} \mathrm{Am}$, these applied corrections were more substantial ( $\sim 40$ to $60 \%$ ), although they do not play a major role for the assessment of the total Am concentration as ${ }^{242} \mathrm{Am}$ has only a minor abundance in the investigated fuel samples (Table 4). The most important correction had to be made for the ${ }^{241} \mathrm{Pu}$ interference on ${ }^{241} \mathrm{Am}$. That adjustment amounted to $\sim 30 \%$ for sample MET 1-4 (fuel sample less doped with $0.6 \mathrm{wt} \% \mathrm{Am}$ ) and $~ 5 \%$ for sample MET 1-7 (fuel sample doped with $1.6 \mathrm{wt} \% \mathrm{Am}$ ), respectively. Compared to the total Am concentration in these samples (Table 3) that correction corresponds to a value of $\sim 19 \%$ and $\sim 2.3 \%$ respectively.

Excellent agreement between the measured Am isotopic composition (corrected for spectral interference) and the calculated data (ORIGEN-2) is highlighted in Table 4. One should consider, however, that both data sets are not completely independent from each other as some calculations have been used to interpret the experimental data, i.e. de-convolution of isobaric interference. But additional supporting evidence for the consistency of the actinide data is provided by the good conformity between the measured and calculated isotopic compositions of other actinides like $\mathrm{Pu}$ and $\mathrm{Cm}$ as well (data not shown). The uncertainty of the results in Table 4 is very difficult to assess as the uncertainty of the ORIGEN-2 calculations is not well defined.

Table 3 Comparative in-house measurements of the Am concentration $\left[\mu \mathrm{g} \mathrm{g}^{-1}, \pm 1 \mathrm{~s}\right.$ ] of the three spent fuel solutions employing sector field ICP-MS $(N=6)$ and ICP-OES $(N=4)$

\begin{tabular}{lcc}
\hline Spent fuel & ICP-MS $^{a}$ & ICP-OES $^{b}$ \\
\hline (Th,Pu)O & & $15.1 \pm 1.3$ \\
MET 1-4 & $15.75 \pm 0.26^{c}$ & $53.9 \pm 1.4$ \\
MET 1-7 & $51.7 \pm 2.7$ & $227 \pm 7$
\end{tabular}

${ }^{a}$ Results are based on external calibration with ${ }^{238} \mathrm{U}$, corrected for the mass bias. Refer to text for more details. ${ }^{b}$ Results have been calculated applying external calibration and using the emission signal at $\lambda=408.929 \mathrm{~nm} .{ }^{c}$ Result of $\gamma$-spectrometry combined with SF-ICPMS after chemical separation of Am as described in ref. 10.

Table 4 Isotopic abundance [weight\%] of Am in the two metallic spent fuels assessed experimentally using sector field ICP-MS and comparison to predictive model calculations (ORIGEN-2)

\begin{tabular}{llllll}
\hline & MET 1-4 & & & \multicolumn{2}{c}{ MET 1-7 } \\
\cline { 2 - 3 } \cline { 5 - 6 } $\mathrm{Wt} \%$ & SF-ICP-MS & ORIGEN-2 & & SF-ICP-MS & ORIGEN-2 \\
\hline${ }^{241} \mathrm{Am}$ & 43.1 & 44.1 & & 41.6 & 40.6 \\
${ }^{242} \mathrm{Am}$ & 1.8 & 2.1 & & 0.9 & 1.0 \\
${ }^{243} \mathrm{Am}$ & 55.0 & 53.8 & & 57.5 & 58.4
\end{tabular}


However, in a conservative estimate one would state a minimum of $5 \%(1 s)$ for the isotopic composition data of the major isotopes ${ }^{241} \mathrm{Am}$ and ${ }^{243} \mathrm{Am}$. The uncertainty of the final concentration data is estimated to be $7.5 \%(1 s)$ for the major Am isotopes individually, resulting in an uncertainty on the total Am concentration of about $5.2 \%(1 s)$ (see Table 3 ).

Comparison between ICP-OES and sector field ICP-MS. Applying the optimised ICP-OES and ICP-MS procedures, the Am concentrations in the mother solutions of three dissolved spent fuels have been analysed by both instrumental approaches. It is important to stress that no separation of either Am or other elements from these mother solutions was carried out prior to analysis. In other words, besides the matrix elements U, Pu and Th, the analyte solutions also contained all fission products as well as minor actinides generated during irradiation of the fuels in the nuclear reactors, representing complex real-world samples. For the predominantly analytical purpose aimed at here, no decay correction of the Am results was necessary because both ICP-OES and ICP-MS analyses were carried out within a couple of days starting from the same solutions prepared simultaneously.

As the ICP-OES Am results obtained at both $\lambda=283.226 \mathrm{~nm}$ and $\lambda=408.929 \mathrm{~nm}$ compared very well with the obtained ICPMS data without fail, these two wavelengths were considered for an accurate quantification of Am. The only restriction concerns the use of the emission line at $\lambda=283.226 \mathrm{~nm}$ in the case of a Th-based fuel (Fig. 1 and Table 2). While the ICP-OES signal at $\lambda$ $=408.929 \mathrm{~nm}$ provides accurate results at all times, the emission line at $\lambda=283.226 \mathrm{~nm}$ can additionally be used only in the absence of Th to confirm the $\lambda=408.929 \mathrm{~nm}$ data.

Because of this important limitation, the following comparison of ICP-MS and ICP-OES analyses is based on the ICP-OES results obtained at $\lambda=408.929 \mathrm{~nm}$. Moreover, the isotopic shift between ${ }^{241} \mathrm{Am}$ and ${ }^{243} \mathrm{Am}$ of $0.86 \pm 0.38 \mathrm{pm}^{5}$ at this wavelength is especially small and close to the guaranteed mechanical reproducibility of $0.4 \mathrm{pm}$ of the employed ICP-OES instrument, thereby minimizing potential deteriorating impacts related to the presence of various Am isotopes in the analyte solution.

The comparative results, summarised in Table 3, highlight the favourable agreement of the Am results obtained by both instrumental techniques. The mean Am concentration for each spent fuel assessed via ICP-OES and ICP-MS differed at most by $4 \%$ from each other with the reported standard deviations of the means always overlapping (Table 3). Considering the experimental complexities associated with these analyses, there is excellent agreement between ICP-OES and SF-ICP-MS results, underlining the accuracy of both analytical methods.

The determination of both the Am concentration and the Am isotope abundance in a non-separated fuel using SF-ICP-MS requires additional information (for example $\gamma$-spectrometry data or ORIGEN-2 calculations) to resolve isobaric spectral interferences. While the ICP-OES analysis allows for the straight-forward, accurate assessment of the Am concentration in non-separated spent fuel solutions, SF-ICP-MS has the potential to provide reliable information on both the Am concentration and the Am isotopic composition.

\section{Acknowledgements}

The support of B. Lynch for preparing the spent fuel solutions in the hot cell facilities of JRC-ITU is gratefully acknowledged. The authors are indebted to Dr H. Ohta from the Central Research Institute of Electric Power Industry (CRIEPI), Japan, for providing ORIGEN-2 data for the two investigated spent metallic fuels.

\section{References}

1 G. R. Choppin, J.-O. Liljenzin and J. Rydberg, Radiochemistry and Nuclear Chemistry, Butterworth-Heinemann, 3rd edn, 2002, ISBN 0-7506-7463-6.

2 X. Claudon, J. C. Birolleau, M. Lavergne, B. Miche and C. Bergey, Spectrochim. Acta, Part B, 1987, 42, 407-411.

3 E. A. Huff and D. L. Bowers, Appl. Spectrosc., 1990, 44, 728729.

4 A. Sengupta, V. C. Adya and S. V. Godbole, J. Radioanal. Nucl. Chem., 2012, 292, 1259-1264.

5 M. Krachler, R. Alvarez-Sarandes, P. Carbol, R. Malmbeck and S. Van Winckel, Microchem. J., 2013, 110, 425-434.

6 K. G. W. Inn, C. M. Johnson Jr, W. Oldham, S. Jerome, L. Tandon, T. Schaaff, R. Jones, D. Mackney, J. Griggs, P. MacKill and B. Palmer, J. Radioanal. Nucl. Chem., 2013, 296, 5-22.

7 M. Krachler, S. Van Winckel, M. Cardinale, B. Lynch and T. Murakami, Microchem. J., 2012, 105, 9-14.

8 M. Krachler, R. Alvarez-Sarandes and S. Van Winckel, J. Anal. At. Spectrom., 2013, 28, 114-120.

9 P. Carbol, R. Malmbeck, M. Krachler, R. Alvarez-Sarandes, Determination of separated Am using $\gamma$-spectrometry, JRC Technical Report, JRC 76009, European Commission, 2012.

10 S. Van Winckel, L. Aldave de las Heras, P. Carbol, E. Hrnecek, R. Malmbeck, P. Van Belle, E. Zuleger, J.-P. Glatz, LWRDeputy Project: Radiochemical analysis of a high burn-up ( Th, $\mathrm{Pu}) \mathrm{O}_{2}$ sample, irradiated in KWO Obrigheim, JRC Scientific and Technical Reports, JRC-ITU-TPW-2010/03, confidential, European Commission, 2010.

11 D. Papaioannou, M. Ougier, V. V. Rondinella, J.-P. Glatz, H. Ohta, Post-Irradiation Examinations (PIE) on the U-Pu$\mathrm{Zr}$ Metal Alloy Fuel Rods from the METAPHIX-1 Experiment, JRC Scientific and Technical Reports, JRC-ITUTPW-2010/04, confidential, European Commission, 2010.

12 M. C. Edelson, E. L. DeKalb, R. K. Winge and V. A. Fassel, Spectrochim. Acta, Part B, 1986, 41, 475-486.

13 P. S. Goodall and S. G. Johnson, J. Anal. At. Spectrom., 1996, 11, 57-60.

14 M. Krachler and P. Carbol, J. Anal. At. Spectrom., 2011, 26, 293-299.

15 M. Krachler and D. H. Wegen, J. Anal. At. Spectrom., 2012, 27, 335-339.

16 G. C.-Y. Chan, X. Mao, I. Choi, A. Sarkar, O. P. Lam, D. K. Shuh and R. E. Russo, Spectrochim. Acta, Part B, 2013, 89, 40-49.

17 A. G. Croff, A User's Manual for the ORIGEN2 Computer Code, ORNL/TM-7175 July 1980. 